\title{
Clustering of Pregnancy Wastages among Young HIV-Positive Women in a High HIV Prevalence District in India
}

\author{
Shajy Isac ${ }^{1,2}$, Shiva Halli ${ }^{2}$, James Blanchard ${ }^{2}$, Stephen Moses $^{2}$ \\ ${ }^{1}$ Karnataka Health Promotion Trust (KHPT), Bengaluru, India \\ ${ }^{2}$ Centre for Global Public Health, Department of Community Health Sciences, University of Manitoba (UoM), Winnipeg, Canada \\ Email: shajyisac@khpt.org
}

How to cite this paper: Isac, S., Halli, S., Blanchard, J. and Moses, S. (2017) Clustering of Pregnancy Wastages among Young HIV-Positive Women in a High HIV Prevalence District in India. World Journal of AIDS, 7, 204-216.

https://doi.org/10.4236/wja.2017.73016

Received: August 2, 2017

Accepted: September 11, 2017

Published: September 14, 2017

Copyright $\odot 2017$ by authors and Scientific Research Publishing Inc. This work is licensed under the Creative Commons Attribution International License (CC BY 4.0).

http://creativecommons.org/licenses/by/4.0/

\begin{abstract}
Context: This paper examined the clustering of pregnancy wastage among HIV-infected pregnant women, particularly focusing on the outcomes of abortions and stillbirths, from a large sample of HIV-positive women to bridge the existing information gap. Methods: Data from a cross-sectional survey conducted among currently married HIV positive women aged 15-29 years in Bagalkot district, Karnataka, India were used. Further to assess the clustering of pregnancy wastage, the binomial distribution was used. Results: The study shows that $2 \%$ of the women account for $32 \%$ of the total pregnancy wastages and $7 \%$ of all the interviewed HIV positive women account for $62 \%$ of the total pregnancy wastages. The study further shows that a higher percent observed (29.6\%) than expected (15.5\%) who had experienced 2 pregnancy wastages suggesting $14.1 \%$ more women experienced 2 pregnancy wastages than expected. Again, a positive deviant of 19.2 among women with at least 3 pregnancy wastage also suggests a higher observed than expected pregnancy wastages, and suggests clustering of pregnancy wastages among HIV-positive women. After adjusting for the socio-economic characteristics, the variance of the observed and expected has reduced only marginally. Conclusions: Clustering of pregnancy wastages among HIV positive women suggests for an increased attention on reproductive health of this marginalized group. The findings will be useful for the interventions working with WLHA in India, particularly the knowledge of clustering would help policy makers and program implementers to focus on high risk women who are likely to experience multiple pregnancy losses.
\end{abstract}

\section{Keywords}

HIV, Clustering, Pregnancy Wastages, Abortions, Still Births 


\section{Introduction}

Child loss is related to a woman's health which in turn is linked with the number and timing of pregnancies she ever had. Vulnerability to child loss particularly increases when women are infected with HIV and are vulnerable to various reproductive health issues [1] [2] [3]. Moreover, it is also observed that HIV-infected women had a much higher rate of recent history of poor fetal outcomes (late abortions, neonatal deaths, premature delivery) than the non-infected group [4]. Low birth weight is an observed complication in HIV-infected women [5], and negative pregnancy outcomes (abortions and high stillbirths) are significantly higher among HIV-positive women possibly due to low birth weight among other factors [4] [5].

The last two decades have shown that the occurrence of child loss is not uniform in the population. Few women/families have been found to experience higher risk of child/pregnancy loss and hence clustering of child loss in families. Children are prone to inherit from their parents similar genetic characteristics [6]. Also, women tend to adopt similar prenatal practices for all their pregnancies, and their physical environment remains more or less the same throughout the pregnancy period. There are certain random or unobservable factors which lead to the higher risks of child loss among a select group of mothers and the effects of parental practices, and physical environment may remain stronger even after adjusting the effects of known socioeconomic and demographic confounders. These factors could be either biological or behavioural in nature that may or may not be measurable [7] [8]. Keeping the dynamics of biological or genetic factors associated with repeated child loss, it is important to assess the extent of clustering of pregnancy loss among HIV-infected women. Most of the previous studies assessed death clustering focused on general population, whereas studies on clustering of pregnancy wastage among people living with HIV (PLHIVs), who tend to become physiologically weak as a result of HIV infection, are not readily available.

The State of Karnataka in India is considered a high HIV prevalence State, with an average of $0.69 \%$ of adults aged 15 - 49 years estimated to be HIV-positive [9]. The HIV positivity rate among the pregnant women attending Ante Natal Clinic (ANC) during 2012-2013 in the state was 0.53\% [10]. The district of Bagalkot, in Northern Karnataka, is one of the highest prevalence districts in the country, with an HIV prevalence of $2.5 \%$ among the general population in 2009, significantly higher in rural areas than in urban areas [11]. Bagalkot (1.15\%) was the only district in the state that had an HIV positivity rate of greater than $1 \%$ among pregnant women tested in 2010-2011 [12]. The district has also reported relatively high levels of neonatal and child mortality compared to many other districts in the state [13]. Therefore, this paper examines the clustering of pregnancy wastage among HIV-infected pregnant women (HIV-1) in Bagalkot district, particularly focusing on the outcomes of abortions and stillbirths, from a large sample of HIV-positive women to bridge the existing information gap. 


\section{Methods and Materials}

The details of the study design and sample size have been published previously [14]. In brief, a randomly selected group of 720 currently married HIV-positive women aged 15 - 29 years from a high HIV-prevalence district of Bagalkot, Karnataka, India were interviewed in the year 2013. The sample size for the study was restricted to married women, as in the context of Karnataka, childbearing is an option mainly for married women [14]. The married young HIV positive women enrolled in Jeevan Jyoti, a Community Based CBO formed for HIV positive people, were stratified into three age groups: 15 - 19 years, 20 - 24 years and 25 - 29 years, and then the required number of respondents (720) were randomly selected from each stratum proportionately. Of the 720 participants recruited, 633 participated (87\% response), and were administered a structured, pre-tested questionnaire in a face-to-face interview. The approach used to examine the clustering is to fit a suitable model to understand whether the distribution of the number of pregnancy wastage for a woman systemically follows some pattern. For instance, one can assess the extent of heterogeneity or clustering of pregnancy wastage using a binomial distribution of the difference between the observed and expected amount of pregnancy losses. This approach estimates the distribution of failure to be expected in a given number of trials with a constant probability of failure. Also, this procedure estimates the expected distribution of pregnancy loss in a group of conceptions, which are subjected to a given risk of termination. An excess of the observed number of women with a different number of pregnancy loss over the expected number indicates clustering. If the null hypothesis (Ho) of no clustering is violated, departure from the chance distribution can be assessed by a $\chi 2$ test, where the observed distribution of pregnancy wastage is compared with the expected distribution of pregnancy wastage under Ho.

In the survey, there were 579 women in the age group 15 - 29 years who had at least one pregnancy at the time of survey. As stated, assuming a constant probability of failure among all women within the group studied, the proportion of pregnancy wastage $(\mathrm{p})$ was 0.1146 , and therefore, the proportion of pregnancies resulted in live birth $(\mathrm{q}=1-\mathrm{p})$ was 0.8853 . Under the null hypothesis of no clustering, i.e., every woman experiences the same risk of pregnancy wastage and the distribution of women by the number of pregnancy wastage is binomial. Then the probability of observing $\mathrm{k}$ pregnancy losses for women with parity $\mathrm{n}$ is given by:

$$
\mathrm{P}(\mathrm{X}=\mathrm{k})=\frac{\mathrm{n} !}{\mathrm{k} !(\mathrm{n}-\mathrm{k}) !} \mathrm{p}^{\mathrm{k}}(1-\mathrm{p})^{\mathrm{n}-\mathrm{k}} ; 0<\mathrm{k}<\mathrm{n}
$$

Accordingly, probability of observing $\mathrm{k}$ pregnancy wastages for parity 1 women is given by

$$
\mathrm{P}[\mathrm{X}=\mathrm{k}]=\frac{1 !}{\mathrm{k} !(1-\mathrm{k}) !} \mathrm{p}^{\mathrm{k}}(1-\mathrm{p})^{1-\mathrm{k}} ; \mathrm{k}=0,1
$$


Probability of observing 0 pregnancy wastage for women in parity 1 is,

$$
\mathrm{P}[\mathrm{X}=0]=\mathrm{p}^{0}(1-\mathrm{p})^{1}=\mathrm{q}
$$

and the probability of observing 1 pregnancy wastage for women of parity 1 is:

$$
\mathrm{P}[\mathrm{x}=1]=\mathrm{p}^{1}(1-\mathrm{p})^{0}=\mathrm{p} .
$$

Similarly, we can estimate the probability of observing $\mathrm{k}$ pregnancy wastage for women at parity $\mathrm{j}$.

Further, expected number of women to experience $j$ pregnancy wastage at age i

$$
E(j)=\frac{S w_{i} P\left[X=j^{1 / 2} i\right]}{S w_{i}} .
$$

In such a distribution, the mean number of pregnancy loss among women with $n$ pregnancies is $n p$, and the variance is $n p(1-p)$. To examine the clustering of pregnancy loss under the null hypothesis that all pregnancies are subjected to the same risk of wastage, we assume the parameter $\mathrm{p}$ as the probability of failure in all women, i.e., the observed proportion of pregnancies lost among all pregnancies of women of a particular age. Further, the expected number of pregnancy wastage is calculated separately for each parity and weighted by the number of women in that parity and then combined across all the parities to obtain the expected distribution of pregnancy wastage, which is then compared with the observed distribution of pregnancy wastage.

In the second approach, we examine the extent of over-dispersion in the observed number of pregnancy wastage relative to expected by deriving the ratio of the observed variance of the number of pregnancy wastage to the expected binomial variance. The expected binomial variance is computed for each parity and then weighting it by a number of women in that parity and combining across all the parities to obtain the expected variance. Thus, the expected binomial variance in $w$ women with parity $j, j=1,2, \cdots, n$; is $s_{j}=n p(1-p)$.

If $w_{j}$ is the number of women of parity $j, N=\sum w_{j}, d_{j}$ is the observed mean number of pregnancy wastage among women of parity $j$, then for all parities combined, the expected binomial variance is:

$$
\mathrm{s}={\frac{1}{N_{j}}}^{\mathrm{s}}\left(\mathrm{w}_{\mathrm{j}} \mathrm{s}_{\mathrm{j}}\right)+{\frac{1}{\mathrm{~N}_{j}}}^{\mathrm{s}}\left(\mathrm{w}_{\mathrm{j}} \mathrm{d}_{\mathrm{j}}^{2}\right)-\mathrm{d}^{2}
$$

where, $d$ is the weighted average of $d_{j}$.

By comparing the observed and expected number of $j$ pregnancy wastage, one can explain the clustering of pregnancy loss in women if there is an excess of observed number of pregnancy wastage over expected. If pregnancy wastage among women tends to cluster, more women would likely to be observed with either no pregnancy loss or with more pregnancy losses than expected.

The study used SPSS 22.0 statistical software. The survey gathered informa- 
tion about women experiencing pregnancy wastage (spontaneous abortion and stillbirths) and the number of such pregnancy wastages. These are the key parameters used to assess the clustering of pregnancy wastage among HIV-infected young women.

\section{Ethical Considerations}

Ethical approval was obtained from the World Health Organization's (WHO) Research Ethics Review Committee, the Health Research Ethics Board of the University of Manitoba, Winnipeg, Canada, and the Institutional Ethical Review Board of St John's Medical College, Bangalore. A written informed consent was obtained from each study participants prior to the interview. Confidentiality of information provided was maintained. Data on any personal identifiers were not recorded in any form.

\section{Results}

Table 1 shows the profile of HIV positive women in the sample. Nearly three-fourth of the respondents was aged 25 and above, mostly belonged to rural areas (72\%) and half of them were illiterates (48\%). Of the total sample, most of them belonged

Table 1. Socio demographic and economic characteristics of young HIV positive respondents.

\begin{tabular}{|c|c|c|c|}
\hline Characteristics & Categories & Number & Percent \\
\hline $\mathrm{n}$ & & 633 & 100.0 \\
\hline \multirow{2}{*}{ Age } & $<25$ years & 168 & 26.5 \\
\hline & $25+$ years & 465 & 73.5 \\
\hline \multirow{2}{*}{ Place of usual residence } & Urban & 179 & 28.3 \\
\hline & Rural & 454 & 71.7 \\
\hline \multirow{3}{*}{ Literacy level } & Literate & 327 & 51.7 \\
\hline & Illiterate & 306 & 48.3 \\
\hline & $<15$ years & 175 & 27.6 \\
\hline \multirow[t]{3}{*}{ Age at living with current husband } & $15-17$ years & 287 & 45.3 \\
\hline & $18+$ years & 170 & 26.9 \\
\hline & $<5$ years & 57 & 9.0 \\
\hline \multirow[t]{2}{*}{ Durations of marriage } & 5 - 9 years & 216 & 34.1 \\
\hline & $10+$ years & 359 & 56.7 \\
\hline \multirow{3}{*}{ Literacy of husband } & Literate & 348 & 55.0 \\
\hline & Illiterate & 285 & 45.0 \\
\hline & $\mathrm{SC} / \mathrm{ST}$ & 267 & 42.2 \\
\hline \multirow[t]{3}{*}{ Caste } & OBC & 177 & 28.0 \\
\hline & Others & 189 & 29.9 \\
\hline & $<\mathrm{US} \$ 50$ & 58 & 9.2 \\
\hline \multirow{3}{*}{ Monthly $\mathrm{HH}$ income (INR) } & US\$50 - 83 & 145 & 22.9 \\
\hline & US\$83 - 167 & 275 & 43.4 \\
\hline & US\$167+ & 155 & 24.5 \\
\hline \multirow{2}{*}{ Type of family } & Nuclear & 497 & 78.5 \\
\hline & Others & 136 & 21.5 \\
\hline \multirow{2}{*}{ Pregnant since tested positive } & No & 400 & 63.2 \\
\hline & Yes & 233 & 36.8 \\
\hline
\end{tabular}


lower caste: $48 \%$ from scheduled or scheduled tribes and $28 \%$ from other backward classes. Results indicate that nearly three-fourth (73\%) of the women started living with their current husbands before the legal age at marriage of 18 years and $28 \%$ of the women started living with their husbands before the age of 15 years. The median duration of marriage for the couples is 10 years with more than half of them (57\%) married more than 10 years and one-third of them married for 5 - 9 years. The household income distribution showed that nearly $25 \%$ of them earn more than US\$167 with mean income being US\$120. Nearly 40\% of the respondents' household income ranged between US\$83 and US\$167 whereas one-fourth of the respondents' household income ranged between US $\$ 50$ and US\$83. Fourth-fifth of the respondents belonged a nuclear family and had a family size of nearly two children (1.82). Among the respondents, $37 \%$ of them became pregnant after testing HIV positive.

The distribution of women aged 15 - 29 years with respect to the number of pregnancies is presented in Table 2. About $22 \%$ of the women had one pregnancy, $30 \%$ had two pregnancies and $23 \%$ had at least 4 pregnancies. About $82 \%$ of the women never had any pregnancy wastage, $12 \%$ had one pregnancy wastage, $4.5 \%$ and $2.4 \%$ respectively had 2 and 3 or more pregnancy wastages. Furthermore, about $23 \%$ women with 4 and more pregnancies accounted for $66 \%$ of the pregnancy wastages. Again, $49 \%$ of the women had at least 3 pregnancies and account for $83 \%$ of the pregnancy wastages.

Table 2 further shows that $2 \%$ of the women account for $32 \%$ of the total pregnancy wastages among HIV-infected women. While $18 \%$ women had, at least, one pregnancy wastages, $7 \%$ of all the interviewed HIV positive women account for $62 \%$ of the total pregnancy wastages. In other words, not all HIV-positive women experience the same level of pregnancy wastage. While few

Table 2. Percent and cumulative distribution of women and pregnancy wastage by number of pregnancies and pregnancy wastages.

\begin{tabular}{|c|c|c|c|c|c|c|}
\hline & \multicolumn{2}{|c|}{ Total } & \multicolumn{4}{|c|}{ Cumulative } \\
\hline & $\begin{array}{l}\text { Number of } \\
\text { women }\end{array}$ & $\%$ & $\begin{array}{l}\text { Number of } \\
\text { women }\end{array}$ & $\%$ & $\begin{array}{c}\text { Number of } \\
\text { pregnancy wastage }\end{array}$ & $\%$ \\
\hline \multicolumn{7}{|c|}{ Number of pregnancies } \\
\hline & 133 & 23.0 & 133 & 23.0 & 116 & 65.9 \\
\hline $\begin{array}{c}4+ \\
3\end{array}$ & 149 & 25.7 & 282 & 48.7 & 146 & 83.0 \\
\hline 2 & 172 & 29.7 & 454 & 78.4 & 166 & 94.3 \\
\hline & 125 & 21.6 & 579 & 100.0 & 176 & 100.0 \\
\hline \multicolumn{7}{|c|}{$\begin{array}{c}\text { Number of pregnancy } \\
\text { wastages }\end{array}$} \\
\hline & 14 & 2.4 & 14 & 2.4 & 57 & 32.4 \\
\hline $\begin{array}{c}3+ \\
2\end{array}$ & 26 & 4.5 & 40 & 6.9 & 109 & 61.9 \\
\hline $\begin{array}{l}1 \\
0\end{array}$ & 67 & 11.6 & 107 & 18.5 & 176 & 100.0 \\
\hline & 472 & 81.5 & 579 & 100.0 & 176 & 100.0 \\
\hline
\end{tabular}


women experience more pregnancy wastage, there are a group of women who experience less wastage.

We compared the observed and expected proportion of women by number of pregnancy wastages and presented this in Table 3. The results show that there is clustering of pregnancy wastages among HIV-positive women. In fact, some women experience fewer pregnancy wastage than would be expected, while other

Table 3. Observed and expected number of pregnancy wastages by number of pregnancy wastages according to selected characteristics of women.

\begin{tabular}{|c|c|c|c|c|c|c|c|c|c|c|c|c|}
\hline \multirow{2}{*}{ Characteristics } & \multicolumn{4}{|c|}{ Observed (O) } & \multicolumn{4}{|c|}{ Expected (E) } & \multicolumn{4}{|c|}{ O-E } \\
\hline & 0 & 1 & 2 & $3+$ & 0 & 1 & 2 & $3+$ & 0 & 1 & 2 & $3+$ \\
\hline Total & 81.5 & 11.6 & 4.5 & 2.4 & 90.4 & 5.1 & 2.6 & 1.8 & -8.9 & 6.5 & 1.8 & 0.6 \\
\hline \multicolumn{13}{|l|}{ Age } \\
\hline$<25$ years & 77.9 & 15.0 & 5.7 & 1.4 & 87.0 & 8.2 & 3.8 & 1.0 & -9.1 & 6.8 & 1.9 & 0.4 \\
\hline $25+$ years & 82.7 & 10.5 & 4.1 & 2.7 & 92.4 & 3.9 & 2.0 & 1.7 & -9.7 & 6.6 & 2.1 & 1.0 \\
\hline \multicolumn{13}{|c|}{ Place of usual residence } \\
\hline Urban & 82.5 & 10.8 & 5.4 & 1.2 & 93.1 & 3.5 & 2.6 & 0.8 & -10.5 & 7.3 & 2.8 & 0.4 \\
\hline Rural & 81.1 & 11.9 & 4.1 & 2.9 & 90.3 & 5.5 & 2.4 & 1.9 & -9.2 & 6.4 & 1.8 & 1.0 \\
\hline \multicolumn{13}{|l|}{ Literacy level } \\
\hline Literate & 81.5 & 10.3 & 5.8 & 2.4 & 90.0 & 5.0 & 3.5 & 1.5 & -8.5 & 5.3 & 2.3 & 0.9 \\
\hline Illiterate & 81.5 & 12.9 & 3.1 & 2.4 & 92.1 & 4.9 & 1.4 & 1.6 & -10.6 & 8.0 & 1.8 & 0.9 \\
\hline \multicolumn{13}{|c|}{$\begin{array}{l}\text { Age at living with current } \\
\text { husband }\end{array}$} \\
\hline$<15$ years & 77.3 & 13.5 & 4.3 & 4.9 & 89.1 & 5.4 & 2.3 & 3.2 & -11.8 & 8.1 & 2.0 & 1.7 \\
\hline 15 - 17 years & 81.3 & 11.6 & 5.2 & 1.9 & 91.3 & 4.9 & 2.6 & 1.2 & -10.1 & 6.8 & 2.6 & 0.7 \\
\hline $18+$ years & 87.2 & 9.5 & 2.7 & 0.7 & 93.0 & 4.6 & 2.0 & 0.5 & -5.8 & 4.9 & 0.7 & 0.2 \\
\hline \multicolumn{13}{|c|}{$\begin{array}{l}\text { Age gap } b / w \text { current husband } \\
\text { and respondent }\end{array}$} \\
\hline$<5$ years & 85.7 & 9.2 & 4.1 & 1.0 & 93.3 & 4.0 & 2.0 & 0.7 & -7.6 & 5.2 & 2.0 & 0.3 \\
\hline 5 - 9 years & 82.1 & 12.8 & 3.1 & 2.0 & 91.8 & 5.4 & 1.5 & 1.4 & -9.7 & 7.4 & 1.6 & 0.7 \\
\hline $10+$ years & 74.7 & 9.2 & 10.3 & 5.7 & 86.0 & 4.3 & 6.6 & 3.1 & -11.3 & 4.9 & 3.7 & 2.6 \\
\hline \multicolumn{13}{|l|}{ Husband literacy } \\
\hline Literate & 83.2 & 11.1 & 4.4 & 1.3 & 92.0 & 4.7 & 2.5 & 0.8 & -8.8 & 6.4 & 1.9 & 0.4 \\
\hline Illiterate & 79.5 & 12.1 & 4.5 & 3.8 & 90.0 & 5.3 & 2.3 & 2.4 & -10.4 & 6.9 & 2.2 & 1.4 \\
\hline \multicolumn{13}{|l|}{ Caste } \\
\hline $\mathrm{SC} / \mathrm{ST}$ & 83.5 & 10.5 & 4.0 & 2.0 & 91.5 & 5.0 & 2.2 & 1.3 & -8.0 & 5.5 & 1.8 & 0.7 \\
\hline OBC & 78.5 & 13.5 & 5.5 & 2.5 & 90.3 & 5.3 & 2.9 & 1.6 & -11.7 & 8.2 & 2.6 & 0.9 \\
\hline Others & 81.5 & 11.3 & 4.2 & 3.0 & 91.2 & 4.6 & 2.3 & 1.9 & -9.7 & 6.7 & 1.9 & 1.1 \\
\hline \multicolumn{13}{|c|}{ Monthly HH income } \\
\hline$<$ US\$50 & 72.5 & 19.6 & 5.9 & 2.0 & 88.5 & 7.8 & 2.4 & 1.2 & -16.0 & 11.8 & 3.5 & 0.7 \\
\hline US\$50 - 83 & 79.0 & 13.8 & 4.3 & 2.9 & 90.4 & 5.1 & 2.5 & 2.0 & -11.4 & 8.7 & 1.8 & 0.9 \\
\hline US\$83 - 167 & 83.5 & 9.6 & 4.4 & 2.4 & 92.5 & 3.9 & 2.2 & 1.5 & -8.9 & 5.8 & 2.2 & 0.9 \\
\hline US\$167+ & 83.7 & 9.9 & 4.3 & 2.1 & 90.2 & 5.7 & 2.7 & 1.4 & -6.5 & 4.2 & 1.5 & 0.7 \\
\hline \multicolumn{13}{|l|}{ Type of family } \\
\hline Nuclear & 83.3 & 10.8 & 3.7 & 2.2 & 92.0 & 4.4 & 2.1 & 1.5 & -8.8 & 6.4 & 1.7 & 0.7 \\
\hline Others & 75.2 & 14.4 & 7.2 & 3.2 & 87.6 & 6.8 & 3.7 & 1.9 & -12.4 & 7.6 & 3.5 & 1.3 \\
\hline \multicolumn{13}{|c|}{ Pregnant since tested positive } \\
\hline Yes & 77.6 & 14.3 & 5.4 & 2.7 & 89.4 & 6.1 & 2.7 & 1.8 & -11.9 & 8.2 & 2.7 & 0.9 \\
\hline No & 84.0 & 9.8 & 3.9 & 2.2 & 92.1 & 4.2 & 2.3 & 1.4 & -8.1 & 5.6 & 1.6 & 0.8 \\
\hline
\end{tabular}


women experience more pregnancy wastages than expected. A negative deviant of 8.9 in the difference between the observed and expected number of pregnancy wastage for women with no pregnancy wastage explains a lower percentage of women who have experienced no pregnancy wastage than expected. Also, a positive deviant of 6.5 in the difference between observed and expected number of pregnancy wastage for the women shows a higher proportion of women experienced, at least, one pregnancy wastage. Further, a positive deviant of 1.8 and 0.6 for the distribution of women with 2,3 and above pregnancy wastages, respectively, explains a higher level of pregnancy wastage risks in certain women which again indicates the presence of high clustering of pregnancy wastages. If there is no clustering of pregnancy wastages, the observed and expected distribution of pregnancy wastages would have remained similar.

Table 3 further indicates that both individual and household level characteristics determine clustering of pregnancy wastages as shown by the positive deviations in the observed and expected percent of pregnancy wastages by the number of pregnancy wastages. We assessed the extent of clustering of pregnancy wastages among the women in different age groups, viz. less than 25 and $25+$ years. While both the age groups produce a more or less same deviation of the observed distribution of women with no pregnancy wastage than expected, a greater percent deviation in the distribution of women who have experienced 2 or more pregnancy wastages is witnessed among older women than the younger ones. Thus, the deviation identifies that women in both the age groups experience clustering of pregnancy wastages, older women experience more pregnancy wastage than the younger ones and very few are experienced with 2 or more pregnancy wastages. That is, the difference in the observed and expected distribution of women with different number of pregnancy wastages distinguishing the level of clustering.

Findings suggest a higher clustering of pregnancy wastages in urban areas than in the rural areas indicating higher and negative deviation in the observed and expected distribution of women with no pregnancy wastage along with a higher and positive deviation with 1 or 2 pregnancy wastages was observed in urban areas than in rural areas. On the other hand, illiterate women experienced a higher level of clustering than literate women as they had a higher negative deviation with no pregnancy wastage and higher positive deviation with one pregnancy wastage. A similar pattern is also noticed for the husband's literacy level.

The high clustering of pregnancy wastage was also observed among women who started living with their current husband at relatively young ages $(<18$ years) compared to those who started living with their husband at a later age (18+ years). For example, a negative deviation of 11.8 and 5.8 between observed and expected percent of women with no pregnancy wastage respectively among those started living with their husbands prior to the age of 15 years and 18+ years of age, clearly indicates a high level of clustering of pregnancy wastage 
among the women who started cohabitation with their husbands before the age of 18 years as compared to those did so after the 18 years of their age.

While clustering of pregnancy wastages were noticed among all women irrespective of monthly household income, a much higher level of clustering was noticed among women belonging to households having less income compared to those with higher income. For instance, a high level of negative deviation of 16 between the observed and expected distribution of pregnancy wastages among women with monthly income less than 50 US\$ and a less level of negative deviation of 6.5 among those with a household income of at least 167 US\$. This shows income as an important aspect in determining the clustering of pregnancy wastages. Similarly, household level characteristics such as caste and family type also show a varying clustering effect by the household characteristics.

Interestingly, those women who became pregnant since testing HIV-positive were more likely to have a higher level of clustering of pregnancy wastages as compared to those who never became pregnant since testing HIV-positive. This may be due to disruption to the reproductive system following the HIV-infection led increased pregnancy wastages.

The study further examined the clustering effect by the deviation in the observed and expected distribution of pregnancy wastages among those who experienced at least one pregnancy wastage. Table 4 presents the observed and expected distribution of pregnancy wastages by number of pregnancy wastages among the women experienced at least one pregnancy wastage. The negative deviation of 33.3 between observed and expected percent of women with 1 pregnancy wastage shows that about $33 \%$ less women experienced pregnancy wastage than expected. Similarly, a higher percent observed (29.6\%) than expected (15.5\%) who had experienced 2 pregnancy wastages suggest $14.1 \%$ more women experienced 2 pregnancy wastages than expected. Again, a positive deviant of 19.2 among women with at least 3 pregnancy wastage also suggest a higher observed than expected pregnancy wastages. These findings suggest a clustering of pregnancy wastages among HIV-positive women having higher pregnancy wastages.

Comparing the distribution of women according to the number of pregnancy wastages in Table 2 and the distribution of pregnancy wastages in Table 4, we found that almost $62 \%$ of the pregnancy wastages occurred to women where 2 or more pregnancy wastages have occurred (6.9\% of women). Further, an excess of

Table 4. Distribution of pregnancy wastage among women who ever experienced pregnancy wastages.

\begin{tabular}{cccc}
\hline & \multicolumn{3}{c}{ Number of pregnancy wastages } \\
\cline { 2 - 4 } & 1 & 2 & $3+$ \\
\hline Observed (O) & 38.1 & 29.6 & 32.3 \\
Expected (E) & 71.4 & 15.5 & 13.1 \\
O-E & -33.3 & 14.1 & 19.2 \\
\hline
\end{tabular}


$2.4 \%$ between the observed and an expected number of women experienced two or more pregnancy wastages accounting an excess of $33.3 \%$ of all pregnancy wastages which could be attributed to high-risk women.

Heterogeneity in pregnancy wastages adjusting socio-economic and demographic characteristics

Further, to have a detailed idea of heterogeneity in pregnancy wastages, the ratio of the observed and expected variance of the number of pregnancy wastage have been examined (Table 5). A ratio of 1 in the observed and expected variance indicates homogeneity in pregnancy wastage in the population, and a ratio above 1 indicates clustering of pregnancy wastages. At the overall level, the ratio of observed to expected variance is 1.464 suggesting that the pattern of pregnancy wastages observed is higher than what would have been expected and hence the presence of clustering of pregnancy wastages among women living with HIV positive.

To assess the extent of clustering, after adjusting for different socio-demographic and economic characteristics, we compared the distribution of pregnancy wastages with the binomial distribution where the parameter " $p$ " is based on the observed proportion of pregnancy wasted by each category of the variable.

After adjusting for the mother's age, the ratio of the variance of the observed and expected reduced marginally from an overall ratio of 1.464 to 1.451 . Similarly, when accounted for other socio-economic and demographic characteristics, the ratio of variance diminished more in case of age gap between husband and respondent, caste and monthly $\mathrm{HH}$ income as compared to other factors indicates that certain level of clustering was due to these factors. However, the results indicate that the large heterogeneity between women is not likely to have occurred due to socio-demographic and economic factors considered in the study, but can be attributed to the other factors.

Table 5. Distribution of observed and expected number of pregnancy wastages.

\begin{tabular}{llll}
\hline & \multicolumn{2}{c}{ Variance } & $\begin{array}{c}\text { Ratio }= \\
\text { Observed/Expected }\end{array}$ \\
\cline { 2 - 3 } Total & Observed & Expected & 1.464 \\
Age & 0.658 & 0.450 & 1.451 \\
Place of usual residence & 0.658 & 0.454 & 1.454 \\
Literacy level & 0.658 & 0.453 & 1.451 \\
Age at living with current husband & 0.658 & 0.454 & 1.450 \\
Age gap between husband and respondent & 0.658 & 0.454 & 1.431 \\
Literacy of husband & 0.658 & 0.460 & 1.451 \\
Caste & 0.658 & 0.454 & 1.438 \\
Monthly HH income & 0.658 & 0.458 & 1.426 \\
Type of family & 0.658 & 0.462 & 1.446 \\
\hline
\end{tabular}




\section{Discussion}

The study examined the presence of clustering of pregnancy wastages among HIV-positive women in a high prevalence district in India. The study has demonstrated clustering of pregnancy wastages among HIV-infected women in the population. Overall, $6.9 \%$ women experience two or more pregnancy wastages and account for about $61 \%$ of the total pregnancy wastages. Variations in the ratio of the observed and expected variance of the number of pregnancy wastages confirms the presence of heterogeneity in the risk of pregnancy wastages. Previous studies explored that the clustering of child deaths in families and demonstrated part of clustering is due to socio-economic and demographic factors [6] [7] [15]. The present study, however, shows that the variance ratio accounting for the individual or household characteristics of the women has not diminished, and therefore, socio-economic and demographic characteristics selected under the study do not necessarily account for the clustering of pregnancy wastages.

Genetic and ecological factors determine a certain level of clustering of infant deaths [6] [15], however, there could be maternal depletion syndrome as an important factor for clustering of pregnancy wastages among HIV-infected women. The District Level Household Survey [16] showed that in the Bagalkot district of Karnataka, about $4 \%$ of all pregnancies among the general population resulted in spontaneous abortions whereas in case of young, currently married, HIV infected women the prevalence of spontaneous abortion was found to be around $14 \%$ [14]. Pregnancy wastages are repetitive and those women who have already experienced pregnancy wastage are likely to have a higher risk of pregnancy loss [17]. This maternal depletion syndrome can be higher among HIV-infected women. While an HIV infection deteriorates the reproductive systems of HIV-infected women [18], the poor reproductive system itself increases the risk of pregnancy wastages and thereby not all women have the risk of experiencing the similar level of pregnancy wastages. The associations between HIV-infection and pre-term delivery and intrauterine growth retardation also were studied [19]. Evidence also showed that miscarriages, spontaneous abortions and stillbirths were more common in HIV-infected women [1] [2] Based on the above discussion, it can be argued that maternal depletion and disease transmission syndrome tend to contribute not only to the increased pregnancy wastages among women living with HIV, but also increased clustering of pregnancy wastages. This is even more dramatic among women marrying and starting cohabitation with husband at younger ages, i.e., below the age of 18 years.

\section{Implications}

Women who know their HIV status are confronted with a multitude of decisions. One of the most important decisions they need to make is having or not having (additional) children. This is an extremely stressful situation, which can have a strong effect on their decision regarding the pregnancy outcomes. Further studies are needed to explore fertility choices of women living with HIV, giving 
them the opportunity to examine the choice to have (additional) children or not. Furthermore, even if some women living with HIV (WLHA) decide not to have (additional) children, to what extent will they implement that decision if they become pregnant accidentally?

The findings of the study are expected to be useful for the interventions working with WLHA in India. If women have a fear of having a child due to their HIV-positive status, it is imperative to know the key factors that affect this decision and work towards addressing such issues effectively through counseling and directing them towards appropriate health care for high risk pregnancies. For example, if many women are reluctant to have children out of fear for possible abortion, the intervention could expand their work with the communities to create an enabling environment for positive pregnancy outcomes. More importantly, the knowledge of clustering would help policy makers and program implementers to focus on high risk women.

\section{References}

[1] Gray, R.H., et al. (1998) Population-Based Study of Fertility in Women with HIV-1 Infection in Uganda. The Lancet, 351, 98-103.

https://doi.org/10.1016/S0140-6736(97)09381-1

[2] Brocklehurst, P. and French, R. (1998) The Association between Maternal HIV Infection and Perinatal Outcome: A Systematic Review of the Literature and Meta-Analysis. BJOG, 105, 836-848. https://doi.org/10.1111/j.1471-0528.1998.tb10227.x

[3] Stephenson, J.M. and Griffioen, A. (1996) Study Group for the Medical Research Council Collaborative Study: The Effect of HIV Diagnosis on Reproductive Experience. AIDS, 10, 1683-1687. https://doi.org/10.1097/00002030-199612000-00013

[4] Urass, E.J., et al. (1992) The Role of HIV Infection in Pregnancy Wastage in Dar e Salaam, Tanzania. Journal of Obstetrics and Gynaecology of Eastern and Central Africa, 10, 70-72.

[5] Kishore, K.J., et al. (2011) A Profile of HIV Positive Antenatal Women at PPTCT Centre, Kadapa. Indian Journal of Public Health Research \& Development, 2011, 2, 24-26.

[6] Das, M.G. (1990) Death Clustering, Mother's Education and Determinants of Child Mortality in Rural Punjab, India. Population Studies, 44, 489-505. https://doi.org/10.1080/0032472031000144866

[7] Guo, G. (1993) Use of Sibling Data to Estimate Family Mortality Effects in Guatemala. Demography, 30, 15-32. https://doi.org/10.2307/2061860

[8] Sastry, N. (1997) Family-Level Clustering of Childhood Mortality Risk in Northeast Brazil. Population Studies, 51, 245-261. https://doi.org/10.1080/0032472031000150036

[9] International Institute for Population Sciences (IIPS) and Macro International (2008) National Family Health Survey (NFHS-3), India, 2005-06. IIPS, Mumbai.

[10] National AIDS Control Organization (NACO) (2013) HIV Sentinel Surveillance 2012-13: A Technical Brief. NACO and Ministry of Health and Family Welfare, Government of India.

[11] Rajaram, S., et al. (2012) Is HIV Prevalence Declining in Southern India? Evidence 
from Two Rounds of General Population Surveys in Bagalkot District, Karnataka. Sexually Transmitted Diseases, 39, 761-768.

https://doi.org/10.1097/OLQ.0b013e3182656c44

[12] Karnataka State AIDS Prevention Society (KSAPS) (2016) HIV Data for the Year 2011-12. http://www.ksaps.gov.in/pdfs/HIV\%20data\%20Karnataka10-11.pdf

[13] Usha, R., et al. (2013) Neonatal, 1-59 Month, and under-5 Mortality in 597 Indian Districts, 2001 to 2012, Estimates from National Demographic and Mortality Surveys. The Lancet, 40, e219-e226.

[14] Shiva, S.H., et al. (2015) Pregnancy Wastage among HIV Infected Women in a High HIV Prevalence District of India. BMC Public Health, 15, 602. https://doi.org/10.1186/s12889-015-1965-1

[15] Isac, S. (2000) Infant and Child Mortality in Orissa and Kerala: A Study of the Differences in the Levels, Determinants and Individual Frailty. Unpublished Thesis, IIPS, Mumbai.

[16] International Institute for Population Sciences (IIPS) (2010) District Level Household Survey-3 (DLHS-3), India, 2007-08. IIPS, Mumbai.

[17] U.S. Department of Health and Human Services (1982) Reproductive Impairments among Married Couples. In: U.S. Vital and Health Statistics, Series 23, No. 11, National Center for Health Statistics, Hyattsville, 5.

[18] Jordan, E.C., et al. (2015) The Effects of Viral Load Burden on Pregnancy Loss among HIV-Infected Women in the United States. Infectious Diseases in Obstetrics and Gynecology, 2015, Article ID: 362357.

[19] Dreyfuss, M.L., et al. (2001) Determinants of Low Birth Weight among HIV-Infected Pregnant Women in Tanzania. The American Journal of Clinical Nutrition, 74, 814-826.

Submit or recommend next manuscript to SCIRP and we will provide best service for you:

Accepting pre-submission inquiries through Email, Facebook, LinkedIn, Twitter, etc. A wide selection of journals (inclusive of 9 subjects, more than 200 journals)

Providing 24-hour high-quality service

User-friendly online submission system

Fair and swift peer-review system

Efficient typesetting and proofreading procedure

Display of the result of downloads and visits, as well as the number of cited articles

Maximum dissemination of your research work

Submit your manuscript at: http://papersubmission.scirp.org/

Or contactwja@scirp.org 